\title{
Relative Price Variability and Inflation
}

\author{
TAllat MaHmood and ShaHEen A. ButT* \\ INTRODUCTION
}

Inflation in an economy reflects the phenomenon of an overall rise in prices. This rise in prices is mainly determined by the excess demand of many individual goods which prevails in the market [6]. But, if the prices of one group of commodities are moving in one direction and those of another group in a different direction (or even in the same direction but at a markedly different pace), then the concept of overall inflation in an economy becomes vague for any economic analysis.

The picture of inflation can be visualized more precisely in an economy if the distribution of individual commodity inflation is also viewed in relation to the average inflation. Vining-Elwertowski [15] have empirically shown that as the average inflation rises, inflation in most of the commodities remains less than the average inflation while inflation for very few commodities exceeds general inflation, usually by a wide margin. Opposite results obtain with falling inflation. In other words, the distribution of inflation for various commodities is skewed at very high or low inflation while they remain normal at moderate inflation in stable years. Parks [13], Friedman [5] and Vining-Elwertowski [15] also observed a positive relationship between relative price variability and the absolute value of average inflation rate. Cukierman [4] has confirmed this relationship. However, it is still a moot point whether relative price variability is the cause or effect of inflation.

In a study by Afridi and Qadir [1] it has been pointed out that the index used for inflation rate is meaningless and inadequate for any economic analysis if the inflation rate is about the same as the standard deviation for the index. They have emphasized that if the standard deviation for any economic index is too high, it may be more appropriate to break the sample into two or more parts, each having a reasonable standard deviation so that the indices for inflation of different sectors become more predictive and adequate for economic analysis.

Parks [13], on the other hand, has developed a multi-market model of relative price variability and found that relative price variability is determined by

*The authors are Staff Economists at the Pakistan Institute of Development Economics, Islamabad. 
unanticipated inflation and real income. This multi-market model was later extended for an open economy by Blejer and Leiderman [3]. They found some other important determinants of relative price variability such as its variation within and between the sets of traded and non-traded goods and the real money growth. They also observed that the relative price variability is higher in traded goods than in nontraded goods.

The purpose of the present study is twofold. Firstly, we shall try to find out a relationship between relative price variability of individual commodities and inflation rate and, secondly, we shall test the validity of Parks's multi-market model [13]. The plan of the paper is as follows.

Section II discusses the data problems and a brief sketch of the methodology which will be used to analyse the relative price variability. Section III explains the estimation and results. Section IV concludes this study.

\section{DATA AND METHODOLOGY}

\section{Data Problems}

In the present study, we have selected prices of nine commodities for food items, seven for raw material and 13 for manufactured goods. These commodities have been selected in the light of the sample of the CSO study of Wholesale Price Index of Pakistan [11] because the weights (as explained below) used in this study are selected from this source. We have also used retail prices of food goods. Their weights are computed from the data given in the Household Income and Expenditure Survey [12].

Data on prices of different commodities are taken from [9] and [10]. Timeseries data on prices are reported across markets and goods in those sources. However, computation of average prices by assigning equal weights to each market is not favoured by Theil [14], on the ground that prices of good for two different regions (markets) differ substantially because of the differences in consumption patterns, transporatation cost, etc. Therefore, weighted average rather than simple average is more appropriate for an analysis of commodity inflation. Since data on the value of the demand for a particular commodity are not available, we have to rely on simple average rather than on weighted average.

Secondly, the data and prices which we have used in this study pertain to a number of markets in Pakistan. Unfortunately, data for all the markets are not available for every year. For some of the years, the data are not reported for some of the markets, thus affecting the comparability of inflation rates computed for various commodities.

Thirdly, there are some commodities for which prices and their supply (particularly in Sixties) are controlled by the government. This causes a serious problem, especially when the causes of inflation are being identified.

\section{Methodological Issues Relating to Relative Price Variability}

The rate of change in prices between two time periods, $t-1$ and $t$ for the $i$ th commodity is denoted by $\dot{P}_{i t}$ which in other words is the difference in the natural logarithm of prices in two time periods, i.e. $\dot{P}_{i t}=\operatorname{Ln}\left(P_{i t} / P_{i t-1}\right)$. It is the inflation rate of the $i$ th commodity after one year. The index for overall inflation in a sector/ country is a weighted geometric mean of natural logarithmic differences in commodity prices across two years, i.e.

$$
\dot{P}_{t} \quad=\sum_{i=1}^{n} w_{0 i} \dot{P}_{i t} \ldots \quad \ldots \quad \ldots \quad \ldots \quad \ldots
$$

where $W_{0 i}=P_{0 i} q_{0 i} / \sum_{i=1}^{n} P_{0 i} q_{0 i}$ with $P_{0 i}$ and $q_{0 i}$ representing the price and quantity of the $i$ th commodity.

Since the weights $\left(W_{0 i}^{\prime}\right)$ given in the Wholesale Price Index of Pakistan 1969-70 [11] do not add up to 1, i.e. $\sum_{i=1}^{m} W_{0 i}^{*} \neq 1$, we have adjusted them so as to make them add up to unity, i.e. $\sum_{i=1}^{n} w_{0 i}=1$, by using the following formula.

$$
W_{0 i}=W_{0 i}^{\prime}\left(\sum_{i=1}^{n} W_{0 i}^{\prime}\right) / \sum_{i=1}^{m} W_{0 i}^{\prime} \ldots \quad \ldots \quad \ldots
$$

where $m<n$.

The measure of relative price change between time periods $t-1$ and $t$ is given by the weighted sum of squared deviations of individual rate of price change from average inflation $\left(\dot{P}_{t}\right){ }^{1}$ This measure shows the degree to which inflation of individual commodity differs from average inflation. The measure of relative price variability is given by the following expression.

$$
V \dot{P}_{t}=\sum_{i=1}^{n} w_{0 i}\left(\dot{P}_{i t}-\dot{P}_{t}\right)^{2} \quad \ldots \quad \ldots \quad \ldots
$$

Different specifications are often used to find out the type of relationship between relative price variability and the inflation rate. Parks [13] has linearly regressed the relative price variability on absolute value of inflation because in his opinion relative price variability is affected by the magnitude of inflation.

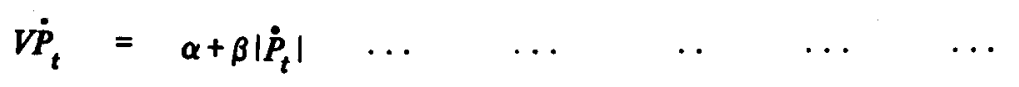

\footnotetext{
${ }^{1}$ See Theil [14].
} 
However, the following non-linear forms can also be used to analyse the relationship between these two variables. ${ }^{2}$

$$
V \dot{P}_{t}=\alpha+\beta\left(\dot{P}_{t}\right)^{2} \quad \ldots \quad \ldots \quad \ldots \quad \ldots
$$

or

$$
V \dot{P}_{t}=\alpha+\beta\left(\dot{P}_{t}\right)+\gamma\left(\dot{P}_{t}\right)^{2}
$$

Blejer and Leiderman [3] have further decomposed inflation into expected inflation and unexpected inflation and argued that relative price variability is more affected by unexpected inflation because it is not anticipated by economic agents. They have used the following specification to test this hypothesis.

$$
V \dot{P}_{t}=\alpha+\beta\left(\dot{P}_{t}-\dot{E P}_{t}\right)^{2}+\gamma\left(\dot{E P}_{t}\right)^{2} \quad \ldots \quad \ldots
$$

where

$$
\begin{aligned}
& \dot{P}_{t}-\dot{P}_{t}=\text { unexpected inflation, and } \\
& \dot{E P_{t} \simeq \dot{P}_{t}}=\dot{\alpha}+\dot{\beta P}_{t-1}=\text { expected inflation. }
\end{aligned}
$$

\section{Methodology for a Multi-Market Model}

Parks's multi-market model, which aims at identifying the determinants of relative price variability, provides a framework for understanding how the basic determinants of supply and demand, combined with expectations about the rate of inflation, affect the amount of relative price variability resulting from changes in nominal income.

The supply and demand equations of the model are specified as follows.

$$
\begin{array}{lll}
\operatorname{Ln} q_{i t}= & a_{0 i}+a_{1 i} \operatorname{Ln}\left(P_{i t} / P_{t}\right)+a_{2 i} T+U_{i} \ldots & \text { Supply equation } \\
\operatorname{Ln} q_{i t}=b_{0 i}+b_{1 i} \operatorname{Ln} P_{i t}+b_{2 i} \operatorname{Ln} \mathrm{Y}+V_{i} \ldots & \text { Demand equation }
\end{array}
$$

where

$q_{i t}=$ quantity of the $i$ th good supplied (demanded) $(i=1,2,3, \ldots . . n)$

$P_{i t} \quad=\quad$ price of the $i$ th good supplied (demanded)

${ }^{2}$ An expression similar to that given by Equation (5) has also beon used by Blejer and Leiderman [3].
$Y=$ nominal income

$T=$ time

$P^{*}=$ an anticipated price level as calculated by regressing $P_{t}$ (average price level) on its lag values, using the following equation.

$P_{t}^{*} \simeq \hat{P}_{t}=\dot{\alpha}_{0}+\dot{\beta}_{0} P_{t-1}$

Supply and demand functions can be written in the logarithmic difference if cross-price elasticities are ignored in the demand function and homogeneity restriction $\left(b_{1 i}+b_{2 i}=0\right)$ is imposed.

$$
\begin{array}{lllll}
\dot{q}_{i t} & =a_{1 i}\left(\dot{P}_{i t}-\dot{P}_{t}\right)+a_{2 i} & \ldots & \ldots & \text { Supply equation (11) } \\
\dot{q}_{i t}=b_{1 i}\left(\dot{P}_{i t}-\dot{Y}_{t}\right) & \ldots & \ldots & \text { Demand equation (12) }
\end{array}
$$

where

$$
\begin{gathered}
\dot{q}_{i t}=\operatorname{Ln}\left(q_{i t} / q_{i t-1}\right), \dot{P}_{i t}=\operatorname{Ln}\left(P_{i t} / P_{i t-1}\right) \\
\text { and } \\
\dot{P}_{t}^{*} \quad=\operatorname{Ln}\left(P_{i t}^{*} / P_{i t-1}^{*}\right) \text { and } \dot{Y}_{t}=\operatorname{Ln}\left(Y_{t} / Y_{t-1}\right)
\end{gathered}
$$

Equations 11 and 12 can be solved to get the following reduced-form equations on the assumption of market clearance condition:

$$
\begin{aligned}
& \dot{P}_{1 t} \quad=\left(1 / a_{1 i}-b_{1 i}\right)\left(-b_{1 i} \dot{\mathrm{Y}}_{t}+a_{1 i} \dot{P}_{t}^{*}-a_{2 i}\right) \quad \ldots \quad \ldots \\
& \dot{q}_{i t} \quad=\left(1 / a_{1 i}-b_{1 i}\right)\left(-a_{1 i} b_{1 i} \dot{Y}_{t}+a_{1 i} b_{1 i} \dot{P}_{t}^{*}-b_{1 i} a_{2 i}\right) \quad \ldots
\end{aligned}
$$

Subtracting $\dot{P}_{t}$ (defined in the previous section) from both the sides of Equation 13 and then squaring the resulting equation, we get the following reduced form:

$$
\begin{aligned}
& V \dot{P}_{t}=A_{0}+A_{1}\left(\dot{Y}_{t}-\dot{P}_{t}\right)^{2}+A_{2}\left(\dot{P}_{t}-\dot{P}_{t}^{*}\right)^{2}+A_{3}\left(\dot{Y}_{t}-\dot{P}_{t}\right)\left(\dot{P}_{t}-\dot{P}_{t}^{*}\right) \\
& A_{4}\left(\dot{Y}_{t}-\dot{P}_{t}\right)+A_{s}\left(\dot{P}_{t}-\dot{P}_{t}^{*}\right) \quad \ldots
\end{aligned}
$$$$
\text { i. }
$$ 
where

$$
\dot{Y}_{t}-\dot{P}_{t}=\text { growth in real income, and }
$$$$
\dot{P}_{t}-\dot{P}_{t}^{*}=\text { unexpected inflation. }
$$

Now if we assume standard forms of supply and demand functions, with $a_{1 i}>0$ and $b_{1 i}<0$, then $A_{0}>0, A_{1}>0, A_{2}>0, A_{3}<0, A_{4}<$ and $A_{5}>0[13] .^{3}$

\section{RESULTS}

We have tested Equations 4, 5 and 6 for food goods, raw material and manufactured goods. The results are shown in Table 1. The relationship between relative price variability and inflation is $U$-shaped in nature. This quadratic relationship is well specified for retail prices of food goods and wholesale prices of raw material because $\bar{R}^{2}$ is reasonably high for these categories of goods.

We have also analysed Equation (5) by comparing it with the rule, adopted by Afridi and Qadir [1], that average inflation is more reliable and has a higher predictive power if twice the standard deviation is equal to or less than the average inflation rate, i.e.

$$
2 \sqrt{V \dot{P}_{t}} \leqslant \dot{P}_{t}
$$

or

$$
\begin{array}{llllll}
\dot{V P} & \leqslant .25 \dot{P}_{t}^{2} & \ldots & \ldots & \ldots & \ldots
\end{array}
$$

We solved Equation (16) simultaneously with Equation (5) (reported in Table 1) to compare the range of inflation rate which satisfies the restriction imposed by Equation (16). Equation (5), estimated for retail prices of food goods, provides the solution values. Twice the standard deviation is less than the values of inflation rate computed for retail prices of food goods, and is equal to or less than 6.9 percent. On the other hand, Equation (5), estimated for other categories of goods, does not give any solution values since all its values are higher than those obtained from Equation (16), which means that each value of inflation for these categories carries a large value of standard deviation (or relative price variability).

We have also tested Equation (7) for each category of goods. The effect of unexpected inflation is pronounced in the case of retail prices of food goods and

${ }^{3}$ The type of relationship of relative price variability with unanticipated inflation and real income is quadratic and a unique minimum value of relative price variability exists at the critical values of $\left(\dot{Y}_{t}-\dot{P}_{t}\right)$ and $\left(\dot{P}_{t}-\dot{P}_{t}^{*}\right)$ because $A_{1}$ and $A_{2}$ are strictly posttive even if we relax the assumption of the standard forms of the supply and demand functions.

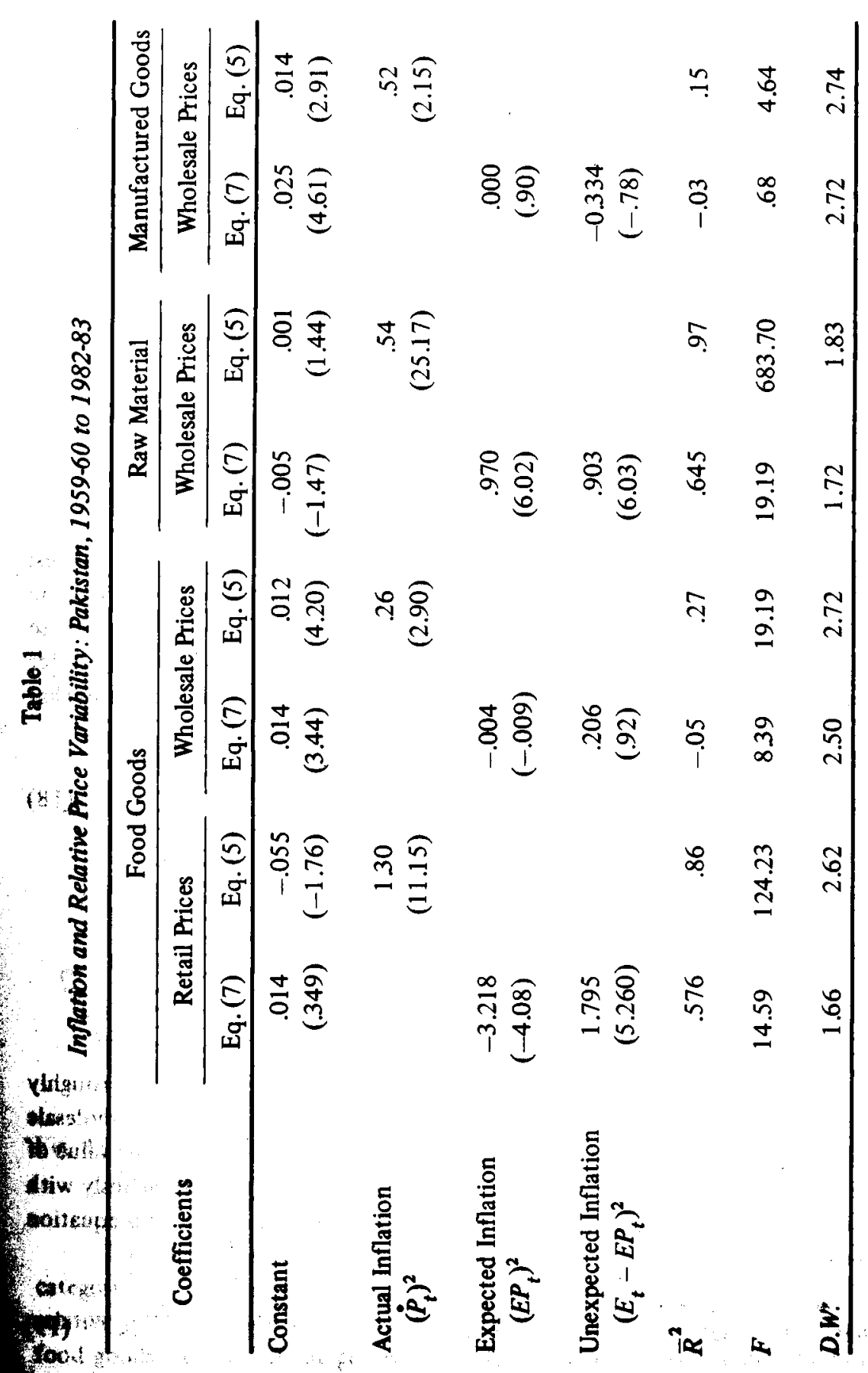


wholesale prices of raw material. This shows that the Blejer-Leiderman hypothesis that relative price variability is more influenced by unexpected inflation is true only for a few categories of goods in the present case.

The estimated Equation (17) shows a positive and insignificant relationship between relative price variability of retail prices and the relative price variability of wholesale prices of food goods.

$$
\begin{aligned}
& R \dot{V P}{ }_{t}=\underset{(-0.19)}{-0.002}+\underset{(1.31)}{0.86} \underset{W V P}{ } \ldots \quad \ldots \quad \ldots \quad \ldots \\
& \bar{R}^{2}=0.13, \quad F=2.91, \quad \text { D.W. }=2.10
\end{aligned}
$$

Roughly, 13 percent of the variation in retail prices is explained by wholesale prices. This partially shows that the economic factors which affect wholesale prices may be different from those factors which determine retail prices. Nevertheless, even if these factors are the same, their intensity to affect the two types of prices may differ significantly for food goods. Secondly, this estimated relationship also indicates that relative price variability is higher in wholesale prices than in retail prices.

$$
\begin{aligned}
\dot{P}_{t}= & \begin{array}{l}
0.03+0.59 \dot{W P}_{t} \ldots \\
(1.83) \quad(4.50)
\end{array} \\
& \bar{R}^{2}=0.52, \quad F=20.25, \quad D . W .=3.17 \\
\dot{P}_{t}= & \text { inflation in retail prices of food goods, and } \\
\dot{W P_{t}}= & \text { inflation in wholesale prices of food goods. }
\end{aligned}
$$

On the other hand, Equation (18) estimated for food goods, explains that roughly 52 percent of inflation in retail prices is determined by the inflation in wholesale prices. Further, to find the value of inflation in wholesale prices at which the value of inflation in retail prices is equal to it, we solved Equation (18) simultaneously with the equation of the line along which the two inflation rates are equal. This equation is given by:

$$
\dot{R P}_{t}=\dot{W P}_{t}
$$$$
\cdots
$$$$
\cdots
$$$$
\cdots
$$

This gives a value of 7.3 percent at which both the inflation rates are equal. The graphs of Equations 18 and 19 are shown in Fig. 1. They intersect each other at a point where values of both the inflation rates is 7.3 percent. This fig. also tells us that the rate of inflation in wholesale prices is smaller than that in retail prices for all the values above this critical value, while the opposite is true for the values below it

Going back to Equation (15), which is composed of three factors, viz. growth in real income $\left(\dot{Y}_{t}-\dot{P}_{t}\right)$, unanticipated inflation $\left(\dot{P}_{t}-\dot{P}_{t}^{*}\right)$ and the interaction term $\left(\dot{Y}_{t}-\dot{P}_{t}\right)\left(\dot{P}_{t}-\dot{P}_{t}^{*}\right)$, 'Table 2 reports the regression results of this equation for food goods, raw material and manufactured goods. $\bar{R}^{2}$ is reasonably high for the retail prices of food goods and wholesale prices of raw material. However, wholesale prices for food and manufactured goods are poorly explained by the given independent variables.

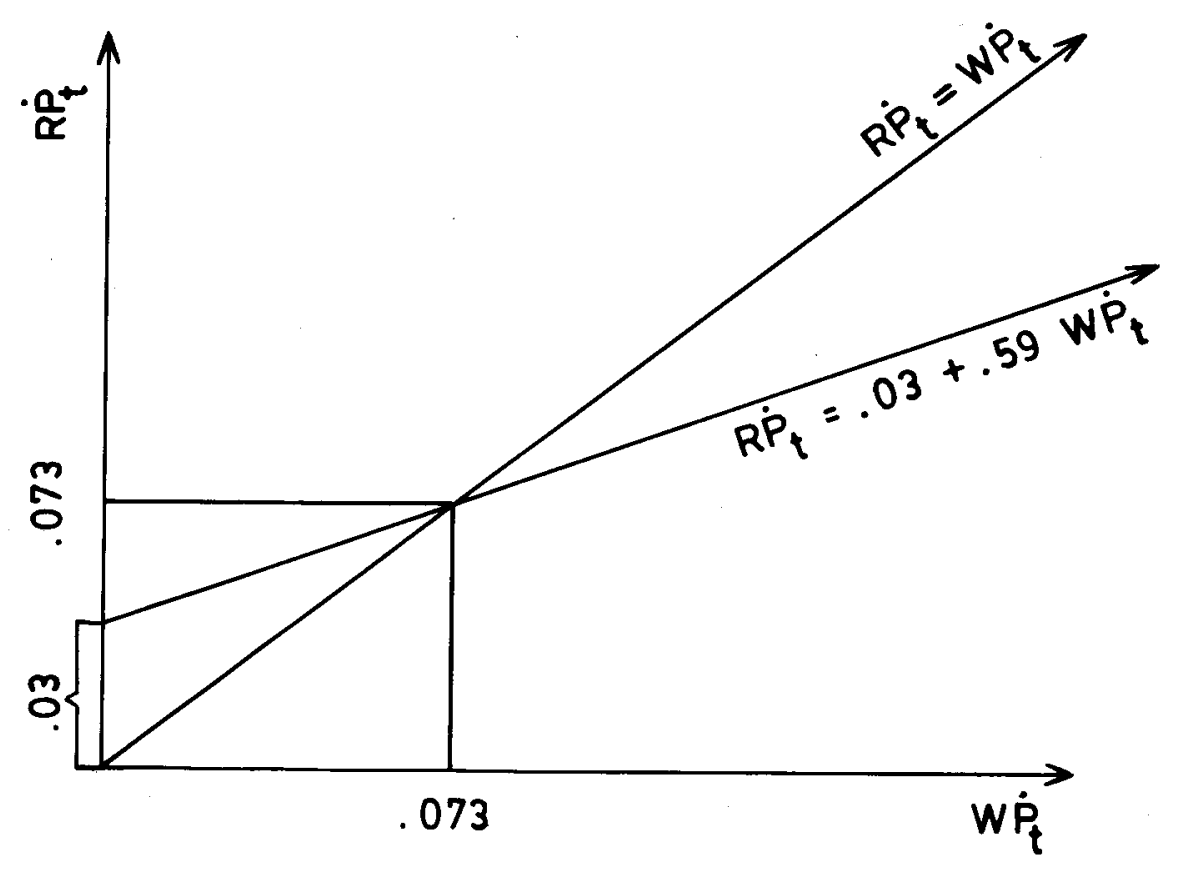

Fig. 1. Relationship between Inflation Rate of Wholesale and Retail Prices of Food Goods

The signs of the parameters from $A_{0}$ to $A_{5}$ are observed to be correct for the

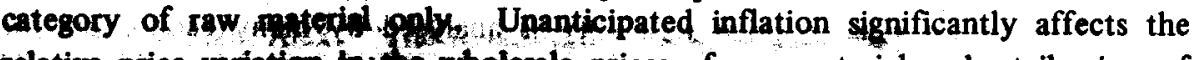

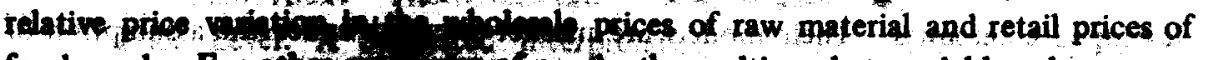

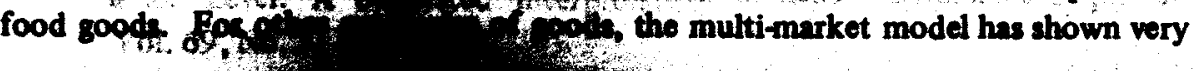


Table 2

Regression Results

\begin{tabular}{|c|c|c|c|c|c|}
\hline Coefficients & $\begin{array}{l}\text { Independent } \\
\text { Variables }\end{array}$ & $\begin{array}{l}\text { Food } \\
\text { Goods } \\
\text { Retail } \\
\text { Prices }\end{array}$ & $\begin{array}{l}\text { Food } \\
\text { Goods } \\
\text { Whole- } \\
\text { sale } \\
\text { Prices }\end{array}$ & $\begin{array}{c}\text { Raw } \\
\text { Material } \\
\text { Whole- } \\
\text { sale } \\
\text { Prices }\end{array}$ & $\begin{array}{c}\text { Manufac- } \\
\text { turing } \\
\text { Goods } \\
\text { Wholesale } \\
\text { Prices }\end{array}$ \\
\hline$A_{0}$ & (constant) & $\begin{array}{r}-0.002 \\
(-1.78)\end{array}$ & $\begin{array}{r}-0.002 \\
(0.22)\end{array}$ & $\begin{array}{r}0.009 \\
(1.96)\end{array}$ & $\begin{array}{r}0.003 \\
(0.19)\end{array}$ \\
\hline$A_{1}$ & $\left(\dot{Y}_{t}-\dot{P}_{t}\right)^{2}$ & $\begin{array}{l}-7.157 \\
(-1.71)\end{array}$ & $\begin{array}{c}-1.319 \\
(-.38)\end{array}$ & $\begin{array}{l}0.597 \\
(0.96\end{array}$ & $\begin{array}{l}0.0001 \\
(1.13)\end{array}$ \\
\hline$A_{2}$ & $\left(\dot{P}_{t}-\dot{P}_{t}^{*}\right)^{2}$ & $\begin{array}{r}1.449 \\
(6.16)\end{array}$ & $\begin{array}{r}0.154 \\
(0.84)\end{array}$ & $\begin{array}{c}0.633 \\
(3.83)\end{array}$ & $\begin{array}{c}-8.935 \\
(-1.57)\end{array}$ \\
\hline$A_{3}$ & $\left(\dot{Y}-\dot{P}_{t}\right)\left(\dot{P}_{t}-\dot{P}_{t}^{*}\right)$ & $\begin{array}{r}1.157 \\
(0.81)\end{array}$ & $\begin{array}{c}-1.909 \\
(-1.16)\end{array}$ & $\begin{array}{c}-1.056 \\
(-1.18)\end{array}$ & $\begin{array}{r}0.012 \\
(0.53)\end{array}$ \\
\hline$A_{4}$ & $\left(\dot{Y}_{t}-\dot{P}_{t}\right)$ & $\begin{array}{r}0.853 \\
(1.30)\end{array}$ & $\begin{array}{r}0.288 \\
(1.81)\end{array}$ & $\begin{array}{r}-0.041 \\
(2.42)\end{array}$ & $\begin{array}{r}-0.007 \\
(4.51)\end{array}$ \\
\hline$A_{5}$ & $\left.\dot{P}_{t}-\dot{P}_{t}^{*}\right)$ & $\begin{array}{r}0.103 \\
(1.30)\end{array}$ & $\begin{array}{r}0.178 \\
(1.81)\end{array}$ & $\begin{array}{r}0.142 \\
(2.42)\end{array}$ & $\begin{array}{r}0.944 \\
(4.51)\end{array}$ \\
\hline & $\vec{R}^{2}$ & 0.87 & 0.23 & 0.80 & -.08 \\
\hline & F.R. & 68.43 & 2.16 & 17.40 & 0.70 \\
\hline & D.W. & 2.34 & 2.55 & 1.25 & 2.85 \\
\hline
\end{tabular}

poor results. Nevertheless, in the case of manufactured goods, the value of $t$-statistic for the parameter $A_{5}$ is significant, which shows that unanticipated inflation linearly affects the relative price variability in the wholesale prices of manufactured goods.

\section{SUMMARY AND CONCLUSIONS}

The issue of relative price variability is analysed by many economists for developed economies. Their models are market-oriented under the assumption of market clearance. They have related price instability with relative price variability and tested the hypothesis that relative price variability is high when inflation is not fully anticipated by the economic agents.

In the present study, we have initially tested the relationship between relative price variability and inflation and found that the deviation of individual commodity inflation from average inflation is too high for most of the categories of goods. Secondly, it has been found that the relative price variability is higher for wholesale prices than for retail prices of food goods. Thirdly, we have tested the BlejerLeiderman hypothesis and observed that for the wholesale prices of raw materials and retail prices of food goods, the relative price variability is significantly affected by unanticipated inflation. Finally, we tested Parks's multi-market model for Pakistan. This typical model has also shown favourable results only for retail prices of food goods and wholesale prices of raw material. We also observed that relative price variability is mostly explained by unanticipated inflation.

For other categories of goods Parks's model has not worked well. This may be due to a number of reasons. Firstly, the underlying assumption of multi-market model seems to be rigid from the viewpoint of underdeveloped countries. The supply and demand functions are assumed to be stable in the model. However, the stability of these functions is sensitive to many other important factors; e.g. $b_{1 i}$ could be affected over time by the change in the degree of substitutability with other goods, the size of the proportion of buyer's income typically devoted to expenditure on the good, and the length of time over which demand conditions are considered. Similarly, $a_{1 i}$ could be affected by the degree of substitutability of factors of production among different production activities, time trend, etc. Secondly, perfect competition is also rare in the economy, and State controls the relative prices of few goods. As such, prices of some goods are not fully determined by market mechanism. Finally, data problems are also one of the major causes of the poor fit of the multi-market model.

\section{REFERENCES}

1. Afridi, Usman and Asghar Qadir. "Dual Sector Inflation in Pakistan". Pakistan Development Review. Vol.XXII, No. 3. Autumn 1983.

2. Barro, Robert J. "Rational Expectations and the Role of Monetary Policy" Journal of Monetary Economics. Vol. 2, No. 1. January 1976.

3. Blejer, I. Mario, and Leonardo Leiderman. "Inflation and Relative Price Variability in the Open Economy". European Economic Review. Vol. 18, No. 3. July 1982 .

4. Cukierman, Alex. "The Relationship Between Relative Prices and the General Price Level: A Suggested Interpretation". American Economic Review. Vol. 69, No. 3. June 1979. 
5. Friedman, M. "Perspectives on Inflation" Newsweek. June 24, 1975.

6. Hansen, Bent. A Study in the Theory of Inflation. London: George Allen \& Unwin Ltd. 1961.

7. Institute of Development Economics. A Measurement of Inflation in Pakistan 1951-60. Karachi. March 1961. (Monograph No. 4) [This Institute was later renamed as Pakistan Institute of Development Economics and is now located at Islamabad.]

8. Lucas, Robert E., Jr. "Some International Evidence on Output-Inflation Tradeoffs". American Economic Review. Vol. 63, No. 3. June 1973.

9. Pakistan. Central Statistical Office. 25 Years of Pakistan in Statistics, 1947-1972. Karachi. 1972.

10. Pakistan. Statistics Division. Bureau of Statistics. 10 Years of Pakistan in Statistics, 1972-82. Karachi. 1983.

11. Pakistan. Ministry of Finance, Planning and Provincial Coordination, Statistics Division. Wholesale Price Index of Pakistan 1969-70. Karachi. 1977.

12. Pakistan. Ministry of Finance, Planning and Development. Statistics Division. Household Income and Expenditure Survey 1969-70. Karachi. 1973.

13. Parks, Richard W. "Inflation and Relative Price Variability". Journal of Political Economy. Vol. 86, No. 1. February 1978.

14. Theil, Henri. Economics and Information Theory. Amsterdam: North-Holland. 1967.

15. Vining, Daniel R., Jr, and Thomas C. Elwertowski. "The Relationship Between Relative Prices and the General Price Level". American Economic Review. Vol. 66. 1976.

\section{Comments on}

"Relative Price Variability and Inflation"

The relationship between relative prices and the general price level has been frequently explored for the U.S. and other developed countries. It is investigated here for the first time for Pakistan.

Some very interesting findings are presented, namely (1) significant quadratic relationships respectively for relative variations in the retail prices of food goods and wholesale prices of raw materials with the inflation rate; (2) significant causal role of unexpected inflation in explaining relative variations in the prices of food goods at (both the wholesale and retail levels) and wholesale prices of raw materials; and (3) significant relationships between relative wholesale and retail price variability of food goods as well as between the two measures of inflation, respectively.

These findings provide food for thought for many of us who used to ignore the issue of relative price variability when speaking generally about the causes and consequences of inflation. For all this the authors ought to be commended.

However, since this is a first attempt for Pakistan, I feel this paper can stand much improvement at both the conceptual and empirical levels which, as we shall see, are closely interlinked.

First let me clear up some ambiguities in the paper before getting on to the more weighty issues. The authors use the term 'general inflation' throughout the paper without being explicit about the measure (index) whose rate of change they have in mind. For their analysis, the authors appear to use (and I may be wrong) the wholesale price index (Producers Price Index) for food, raw materials, and manufactured goods, and some variant of the consumer price index for food goods as two inflation measures - both with 1969-1970 weights. Some parts of their concluding remarks are loosely worded. Then, somewhere in their paper, the authors state that "From this one can deduce that general price stability can be sustained in the country if state can control the relative price variability by the adjustment/fixation of few important consumer/producer goods prices" (emphasis mine). The implication of it is that if the State were to control all prices, we would have no inflation. I am sure that the authors neither mean it nor believe in this. We are all aware of the severe distortions in resource allocation that this would cause in the economy.

Let me now turn to the major problems in the paper.

Any price index - whether it be the Producers Price Index (PPI) or the Conaumer Price Index (CPI) - is a weighted average of the prices of relevant commodi.

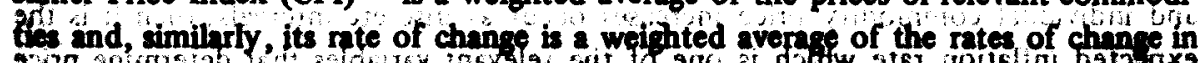
Sinq anifinsto 
various commodity prices. This is defined in the paper as Equation (1). The measure of relative price change is given in Equation (3) as a weighted sum of squared deviations of the commodity prices around the inflation rate. It is evident from Equations (1) and (3) that the inflation rate is determined by individual commodity prices and the commodity price variation is determined partly by inflation rate. We have a problem here in determining what causes what. It is clear that commodity prices and inflation rate are simultaneously determined.

When the authors regress the relative variability $(V \dot{P})$ on the inflation rate $(\dot{P})$ in Equation (4), this procedure is akin to regressing a variance on the mean. Now we have two problems. Ignoring the latter problem for now, the first problem could have been resolved by either conducting Sims-Granger-Weinter type causality tests between the inflation rate and relative price variability variables or simultaneously estimating both variables. As it is, the OLS estimates of this relationship in the paper are biased and inconsistent.

Coming now to the second problem, viz. regressing a variance on the mean, we would expect a quadratic relationship. But this is true by definition, and not something that has been discovered. Therefore, I wonder what new insight has been provided by the authors when they claim that the relationship, on the basis of adjusted $R^{2}$, is a quadratic one, i.e. their Equation (5).

The authors seem to be on the right track when they decompose 'general inflation' into expected and unexpected inflations asserting that relative price variability is more affected by unexpected inflation (coming closer to the new classical economics position). Using an adaptive expectations mechanism they specify Equation (7) in quadratic form again. On examining their results in Table 3, this formulation is found to be significant for food at the retail level and for raw materials at the wholesale level. Whereas the coefficient of the expected inflation term in the food equation has a negative sign, implying an inverse relationship between relative price variability and inflation, we find the two to be directly related for raw materials. No intuitive rationale is provided for these asymmetrical results.

Let us pause and reflect on the kind of ex ante relationship that would exist between the 'general level of inflation' and relative price variability: We know that any commonly used index (such as the CPI) has several shortcomings as a measure of price changes over a period of time - it neglects quality changes, changes in preferences and demand, introduction of new commodities, etc. The authors add to the list of shortcomings, viz. different and changing markets, and the presence of price controls in Pakistan.

In spite of shortcomings, the inflation measure is widely used as a benchmark for wage negotiations, price increases, COLAs, etc. If we assume that wage contracts and individual commodity price increases occur at discrete intervals, then it is the expected inflation rate which is one of the relevant variables that determine price changes. If the inflation rate turns out to be higher than expected due to policy surprises, external shocks and the like, then expectations would be adjusted upwards and eventually (as the rational-expectations school reminds us) the people would not be surprised all the time since they would come to expect these surprises. It was for this reason that I suggested that the authors were on the right track in decomposing the inflation measure into expected and unexpected inflations. The specific nature of this lead-lag, ex ante relationship needs to be well thought out, specifically in the context of Pakistan.

The multi-market model, I think, is a more satisfactory way of finding the determinants of relative price variability, since other factors which determine demand and supply of a particular commodity are taken into account along with the expected inflation rate.

All in all, this study is a trail-blazer for Pakistan. I am aware that this is a preliminary attempt and, therefore, confidently look forward to an excellent finished product.

The Catholic University

of America,

Washington, D.C.

USA
Nasir M. Khilji 